\title{
Equity, Power Games, and Legitimacy: Dilemmas of Participatory Natural Resource Management
}

\author{
Cecile Barnaud $^{1,2,3}$ and Annemarie Van Paassen ${ }^{4}$
}

\begin{abstract}
Many papers in the recent literature on participatory approaches emphasize the need to take better account of the complexity of the social contexts in which they are conducted. Without attention to power asymmetries, there is a risk that the most powerful stakeholders will have greater influence on the outcomes of the participatory process than marginalized stakeholders. However, very few authors address the question of how to deal with such power asymmetries. This question puts designers of participatory processes in a dilemma. On the one hand, if they claim a neutral posture, they are accused of being naively manipulated by the most powerful stakeholders and of increasing initial power asymmetries; but, on the other hand, if they adopt a nonneutral posture and decide to empower some particular stakeholders, their legitimacy to do so is questioned. We test a particular posture to overcome this dilemma: that is, a "critical companion" posture, which strategically deals with power asymmetries to avoid increasing initial power asymmetries, and which suggests that designers should make explicit their assumptions and objectives regarding the social context so that local stakeholders can choose to accept them as legitimate or to reject them. Legitimacy is seen as the product of a coconstruction process between the designers and the participants. This posture was tested in the context of a participatory process conducted in northern Thailand to address a conflict between the creation of a national park and two local communities. While we show that this posture makes it possible for designers to be both strategic and legitimate at the same time, it also raises new questions and new dilemmas. Can we, and should we, really make all our assumptions explicit? How can we deal with stakeholders who refuse to engage in any form of dialog? We conclude that there is no "right" posture to adopt, but that designers need to be more reflexive about their own postures.
\end{abstract}

Key Words: critical systems; inequity; participatory approach; power; reflexivity; transdisciplinarity

\section{INTRODUCTION}

The United Nations Conference held in Rio de Janeiro in 1992 endorsed the concept of sustainable development as a guiding principle and emphasized stakeholder participation as an important means to achieve it (United Nations 1993). Since then, numerous participatory approaches have been developed to promote more dialog between local stakeholders, decision makers, and researchers, in fields such as water management (Pahl-Wostl et al. 2007, Kuper et al. 2009, Von Korff et al. 2012), forest management (Agrawal and Gupta 2005), and agricultural development (Chambers et al. 1989, Pretty 1995). In these fields, participation is seen as a way to deal with the uncertain and complex nature of social-ecological systems and to increase people's adaptive capacity through enhanced social learning for the integrated and adaptive management of natural resources (Gunderson and Holling 2002, Lynam et al. 2002, Walker et al. 2002, Berkes et al. 2003).

However, although the concept of participation intrinsically embodies an objective of social and political equity (Cornwall and Gaventa 2001), lessons from the past tell us that more careful attention needs to be paid to genuinely achieving equitable impacts (Eversol 2003, Johnson et al. 2004, Agrawal and Gupta 2005). Indeed, participatory approaches take place in heterogeneous social contexts characterized by conflicts of interest and power asymmetries (Daré and Barreteau 2003,
Becu et al. 2008, Barnaud et al. 2010). There is a risk of the more powerful stakeholders having greater influence on the outcomes of the participatory process than marginalized and socially disadvantaged stakeholders (Munoz et al. 2007, Sikor and Nguyen 2007). This is why numerous authors highlight the need to better understand the complexity of the social contexts in which participatory processes are conducted (Moity-Maïzi 2000, Edmunds and Wollenberg 2001). Methods such as stakeholder analysis are more and more considered essential to deciding who should be involved in participatory processes (Reed et al. 2009).

Still, despite a growing body of literature that emphasizes the need to better understand power asymmetries among stakeholders, very few authors address the "how" question, that is, how to take into account power asymmetries when designing and implementing a participatory process.

This question is frequently overlooked because it is not so much a matter of method as a matter of posture. The postures adopted by the designers of participatory processes are indeed driven by norms, values, or ideologies that are rarely made explicit. Moreover, the question of how to deal with power asymmetries puts them in a dilemma. On the one hand, if they claim a neutral posture regarding power asymmetries, they are accused of being naively manipulated by the most powerful stakeholders (Cooke and Kothari 2001, Edmunds and

${ }^{1}$ INRA, UMR1201 DYNAFOR, ${ }^{2}$ Toulouse University, INPT-ENSAT, ${ }^{3}$ Toulouse University, INPT EI Purpan, ${ }^{4}$ Knowledge, Technology and Innovation Group, Wageningen University 
Wollenberg 2001) and of taking the risk of the participatory process increasing asymmetries among stakeholders. Therefore, their neutrality is illusory. On the other hand, if they claim a nonneutral posture and empower some stakeholders, they are accused of intervening in a social system and modifying it without having the legitimacy to do so (Innes 2004).

Here, we suggest and test a posture that attempts to overcome this dilemma. This posture, which we call the "critical companion" posture, is a nonneutral posture that recognizes the necessity to take into account power asymmetries to avoid the risk of increasing initial asymmetries. The designer adopting this posture needs to make his underlying assumptions and objectives explicit so that stakeholders can choose to accept them as legitimate or to reject them. Legitimacy is seen as the result of a coconstruction process between designers and stakeholders.

We do not think that this is necessarily the "right" posture to adopt. We do not even believe that such a "right" posture exists. We aim to better understand the complexity of the question of how power asymmetries in participatory approaches should be dealt with by questioning the practical implications of this posture, its coherence, its potential, and its limits, and highlighting the questions that arise when it is adopted.

\section{THEORETICAL INSIGHTS}

\section{Power and participation in development studies}

In this paper, we focus on the issue of power and participation at the local level of social interactions among stakeholders. However, the issue of power and participation is also debated in the larger context of development and North-South relationships. We briefly explain the position of critical social scientists in these larger scale debates, before focusing on the debates regarding the implementation of multistakeholder participatory processes at the local level. Several movements arose in the 1980s as a reaction against development, as it implied the imposition of the western discourse that represented subsistence societies as economically and technically underdeveloped (Escobar 1988). Anti-development theorists took a principled stance against the idea of development, and post-development theorists esteemed that populist movements should make the difference. In practice, development programs have tried to solve the issue via engagement in more bottom-up participatory approaches. However, both anti- and post-development proponents condemn participation because it remains a form of external intervention. As for critical social scientists, they do not reject managerial interventions, but call for critical studies of inherent power dynamics. They note that global civil society has taken the responsibility to advance emancipation; hence, we should carefully study power dynamics as triggered by populist movements as well as by more invited forms of participation to learn how better to support democratic change (Flood and Jackson 1991, Nederveen Pieterse 2000, Ulrich 2000, Hickey and Mohan 2005, Mitlin et al. 2007). They suggest that we should remain cautious about participation "as the wolf of control and subjugation still lurks beneath the new sheep's clothing" (Blaikie 2000:1045).

\section{Dialogical vs. strategic perspectives}

The power issue has also drawn a dividing line among researchers in the field of participatory multistakeholder processes (Faysse 2006). Two main perspectives can be distinguished: dialogical and strategic, inspired respectively by soft-systems theories (Checkland 1981) and critical systems theories (Ulrich 1995, Jackson 2000). The former emphasize the differences in perceptions among stakeholders and their lack of mutual understanding. They consider dialog and communication as the main issue on which to focus to achieve better collaboration among stakeholders (Pretty 1995). Advocates of the strategic perspective underline the limited ability of dialogical approaches to deal with situations that are too conflictive or coercive (Leeuwis 2000). They note that, in these situations, dialog is not sufficient to achieve equitable impacts. According to them, the designers of participatory processes should strategically intervene in multistakeholder settings to ensure that the less influential stakeholders have a chance to voice and assert their interests (Edmunds and Wollenberg 2001). Although these two perspectives are sometimes seen as antagonistic (Faysse 2006), several authors highlight their complementarities (Jackson 2000, Leeuwis 2000, Ulrich 2003, van Paassen et al. 2011). First, as Jackson (2000) noted, it depends on the context. In some situations with few power asymmetries or conflicts of interest, dialog is possible, whereas in other situations in which stakes are higher and more controversial, more strategic facilitation is needed; but even in contexts with high stakes and controversies, dialogical and strategic approaches can be combined and complement each other. A strategic approach dealing with power asymmetries can help unmask such asymmetries and prevent them from dominating the setting; this may open the floor to more dialogical processes that are more driven by argumentation than coercion, i.e., that get closer to Habermas' ideal speech situation (Habermas 1985).

\section{The companion modeling approach: making designers' assumptions explicit}

The posture we tested here is also inspired by the companion modeling (ComMod) approach. This participatory approach is aimed at facilitating collective learning processes among various stakeholders (including researchers) about a common problem in complex social-ecological systems (Bousquet et al. 1999). It is based on the coconstruction of simulation models integrating various stakeholders' perceptions, and the use of these simulation models to jointly explore and discuss 
possible future scenarios. Among the numerous participatory approaches described in the literature, an originality of the ComMod approach is that the researchers who developed it elaborated a chart about the deontological implications of their posture (Barreteau et al. 2003). This chart recognizes the existence of multiple legitimate points of view and considers that the researchers' point of view is just one point of view among others. The assumptions backing the participatory process (definition of objective, choice of methods, etc.) and the modeling activity (scientific assumptions) are purposively submitted to refutation at each interaction with the stakeholders. The approach is adaptive and iterative so that the participants can continuously question, criticize, or validate it. Some ComMod researchers emphasize, in particular, the need for the designers to clarify their objectives and their posture regarding the social context to avoid raising false expectations (Barreteau et al. 2010) and to increase their chance of success (D'Aquino 2007). However, the ComMod chart is not specific about the posture regarding the way to deal with power asymmetries. A recent study showed that the researchers applying this method adopted very contrasting postures; some opting for dialogical postures, and some for more strategic ones (Barnaud et al. 2011). In this paper, we define and test our critical companion posture to explore the compatibility between a critical approach and the deontological requirements of the companion modeling approach. At first sight, one can indeed expect some contradictions between being strategic and being transparent.

\section{Defining a critical companion posture}

The critical companion posture recognizes the need to take power asymmetries into account to avoid the risk of increasing initial social inequities. This is a nonneutral posture. We believe that claiming a neutral posture is problematic not only because of the risk of overlooking power asymmetries and reinforcing them, but also because, if a designer does not make his biases explicit, he risks imposing them unconsciously. However, claiming nonneutrality is not sufficient to overcome the above-mentioned dilemma: if a designer deliberately empowers some particular stakeholders, one can question his legitimacy to be so interventionist in a given social context. Drawing on the companion modeling approach, we suggest that the designer of a participatory process adopting a critical companion posture should, whenever possible, make explicit his assumptions and objectives regarding the social context, so that local stakeholders can decide whether they accept them as legitimate or reject them. Their adhesion to the objectives and assumptions of the participatory process is considered as the main source of legitimacy of this process. In the critical companion posture, the explicit objective is the facilitation of an equitable concerted process, that is, a process in which all stakeholders have an equal chance to voice and assert their interests. Like Habermas' ideal speech situation, this is a theoretical ideal that is useful for the identification of factors that impede its realization, and the elaboration of possible measures to enhance more equitable concertation.

\section{METHODS}

To test the pertinence of this critical companion posture, we applied an action-research methodology, i.e., we conducted on the ground a companion modeling (ComMod) process adopting such a posture. The first author of this paper was the main designer of the process, supported by a team of Thai and French researchers. The second author was not directly involved in the participatory process but contributed to an external evaluation of it. This experiment was conducted in 2006 in northern Thailand in the context of a conflict between a national park being established and two ethnic minority communities located near the future boundaries of the park.

\section{Context and objective of the participatory process}

The highlands of northern Thailand are inhabited by ethnic minorities who have long been accused of degrading the upper watersheds of the country's major basins (McKinnon and Vienne 1989). They used to practice a type of shifting slashand-burn agriculture that was blamed for deforestation, and in 1989 the government enforced a ban on encroachment that forced them to shift to a permanent type of agriculture (Hirsch 1997). In the 1990s, the government reinforced its environmental policies and further restricted their access to land and forest resources through the delimitation of reserved forest areas managed by the Royal Forestry Department and the establishment of new national parks and wildlife sanctuaries. However, at the same time, the policy framework also favored decentralization and public participation (Arghiros 2001). This contradiction resulted in an increased number of conflicts over land use between local communities and state agencies, like the conflict described here.

This conflict took place in the province of Nan, one of the northern provinces of Thailand near the border with Laos, between a new national park and two communities belonging to the Mien ethnic group. The process of the creation of the national park had started in 1996, but in 2006 when the initial diagnosis was conducted, the conflict had reached a peak because the park was meant to be officially declared open the following year, in 2007. Technically, in 2006, the area was still under the management of a local office of the Royal Forestry Department (RFD), established in the early 1990s, that had been in charge of delimiting farm and forest land in each village to prevent further encroachment. After an initial period of conflict with villagers, the RFD officers had adopted more participatory approaches and established informal agreements with them. In particular, they delimited some informal community forests in which farmers could practice their religious rituals and gather nontimber forest products (NTFP). In local farmers' livelihood systems, the collection of NTFP is indeed a key source of food and income, in particular among the most resource-poor households. 
However, according to Thai law, no human activity except tourism is allowed within a national park. The RFD officers tried to convince the chief of the new national park to make some local informal arrangements, but he was not prone to conciliation. In 2006, the relations between the national park and the villagers reflected mutual mistrust and strong prejudices on both sides. The general situation was unclear, with a lot of misinformation among villagers. In particular, the key questions of the future location of the park boundary and the rules to be enforced within the park regarding the collection of NTFP had not yet been discussed beyond a limited circle of village leaders. In this climate of conflict, there was a risk that the chief of the national park would make unilateral decisions or, at best, after consulting a few village leaders only.

In this context, the aim of the ComMod process was to accompany the ongoing negotiation by facilitating a concerted process between villagers and national park officers, while taking into account the diversity of interests among villagers. We emphasized the existence of heterogeneities and power asymmetries within communities because many participatory approaches conducted in northern Thailand failed to take this heterogeneity into account and were dominated by local elites and village leaders (Neef 2005, Becu et al. 2008). The myth of a homogeneous community is indeed very strong in the scientific community studying ethnic minorities (Guijt and Shah 1998). Some authors speak of ethno-romanticism (Neef 2005).

\section{Main principles of the critical companion modeling process}

As in several ComMod processes, two kinds of simulation tools were combined in this process: computer agent-based models (ABM) and role-playing games (RPG). Agent-based models are particularly appropriate to represent complex social-ecological systems because of their ability to represent interactions among heterogeneous social agents and between these agents and their common environment (Ferber 1999, Bousquet and LePage 2004). Role-playing games are an appropriate mode of communication to convey complexity as it allows multiple stakeholders to interactively examine the complex systems of which they are part (Duke 1974). In a RPG, players can discuss and test alternative scenarios of potential solutions, but the use of this tool quickly becomes costly and very time consuming. To remove these constraints, it is possible to build a simple computerized ABM, very similar to the RPG in its features and rules but far more cost and time efficient, to simulate scenarios. Moreover, because the RPG is based on the same conceptual model as the ABM, the use of the RPG can be seen as a way to "open the black box" of the computer ABM (Barreteau et al. 2001). It allows players to understand, validate, and/or criticize and enrich it and, later on, to be able to follow ABM simulations and to comment on their results. Therefore, the model underlying both the ABM and the RPG is built iteratively, based on a combination of knowledge coming from the researchers' observations and the local stakeholders' suggestions.

This ComMod process, conducted with a critical stance (Fig. 1), started with a 4-month, in-depth analysis of the initial agrarian and institutional situation through individual semidirected interviews (approximately 30 farmers, village leaders, national park officers, foresters, etc.) (Barnaud et al. 2008). Drawing on theories of agrarian systems (Mazoyer and Roudart 1997) and institutional analysis (Ostrom et al. 1994), this initial analysis aimed to understand the key natural resource management problem; the key stakeholders; their interests regarding the issue at stake; their perceptions of the situation and of the other stakeholders; and the social interactions among them, including rules of access to resources and power relations. This initial analysis is considered as a key stage of the critical process as it allows us to identify the potential obstacles to an equitable concerted process (Fig. 1). When implementing the participatory process, we made specific choices to try to overcome these obstacles. A reflexive analysis of these nonneutral choices was conducted, following Ulrich's (2003) critical systems thinking approach aimed at promoting reflexivity in operational research, specifically regarding the way to deal with power asymmetries.

Fig. 1. Framework of a ComMod process conducted with critical companion posture.

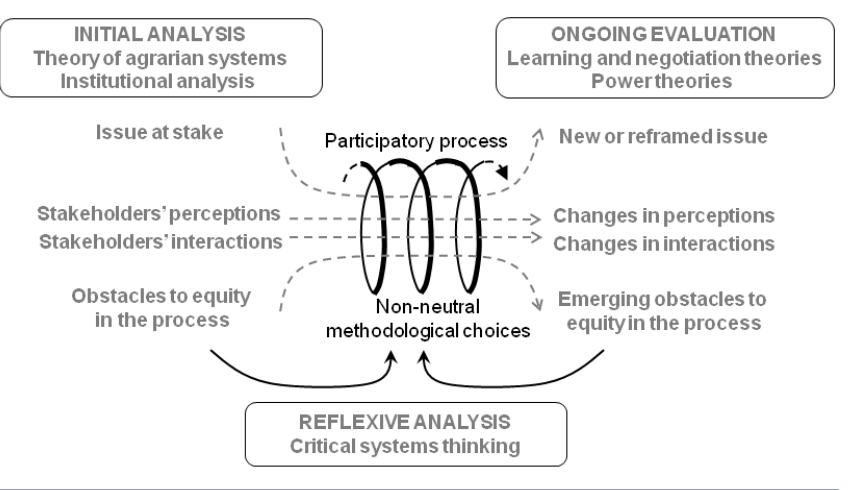

This initial analysis was followed by a series of participatory workshops combining the following activities: (1) RPG sessions in which the participants (farmers and administrators) played their own role and interactively examined the complex systems of which they were part, (2) plenary and subgroup discussions about problems encountered in the game and possible solutions, and (3) computer ABM simulations to explore longer term effects of these solutions and/or to enlarge discussions at village level (more than 50 participating villagers). First, several workshops were conducted in each village to help villagers reflect among themselves on the 
establishment of the national park. Other workshops were organized with national park officers and forest officers to allow them to discuss among themselves the conflict with the villagers. Finally, a workshop was organized with all stakeholders (villagers from both villages, and national park and forest officers) to jointly explore the potential economic, social, and ecological consequences of various sets of possible forest management rules.

Throughout the process, efforts were made to be explicit about the objectives and assumptions backing the process, so as to question and build the legitimacy of the process with the participants. Concretely, we said that our objective was to test a kind of communication platform in which all stakeholders would have an equal chance to voice and assert their interests, and that we assumed that this might facilitate the emergence of win-win solutions. We systematically engaged in discussions with villagers, village leaders, and national park officers to make them express what they thought of the suggested participatory process. We asked them whether the process focus and design met their interests and preoccupations and, if it did not, how it might be possible to design a process that would better meet their expectations. For example, for the final workshop, the chief of the national park expressed his willingness to focus on the forest management rules rather than on the park boundaries, because he felt more comfortable meeting with villagers on this less conflictive issue.

Regarding the monitoring and evaluation process, individual interviews of participants were conducted right after and in between the workshops to monitor the effects of the process in terms of (1) evolution or new definition of the issue at stake, (2) changes in stakeholders' perceptions and interactions (for example: expression and/or evolution of power relations), and (3) obstacles to the emergence of a concerted process (Fig. 1). This evaluation framework is based on learning, negotiation (Leeuwis 2004), and power theories (Giddens 1984, Boulding 1989). This monitoring process was used to adjust the process and the tools to the observed changes in an adaptive way. The described series of workshops was not predetermined but designed step by step, to adjust continuously to the evolution of the local context, the learning and negotiation process among the participants, their preoccupations, and their expectations regarding the ComMod process.

\section{RESULTS}

\section{Some obstacles to the emergence of an equitable concerted process}

A detailed description of the sociopolitical and agroecological context of this case study is available elsewhere (Barnaud et al. 2008). Here, we present the key stakeholders' interests and power relations, and the subsequent potential obstacles to the emergence of an equitable concerted process.
Figure 2 presents a matrix of stakeholders' importance and influence regarding the issue at stake (the establishment of the new national park). Importance refers to the degree to which the stakeholders are potentially affected by the issue at stake, and influence refers to the degree to which they can influence the outcome of this issue (Grimble and Wellard 1997).

Fig. 2. Matrix showing the key stakeholders' relative influence and importance in the national park issue, Nan Province, Thailand.

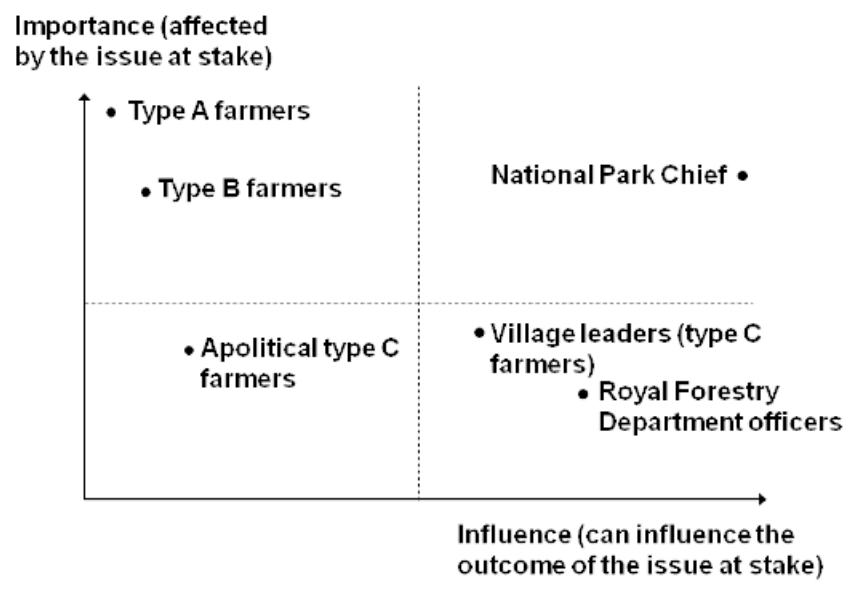

Three main types of farming households were identified within the communities, characterized by different socioeconomic constraints and farming strategies and having consequently contrasting interests regarding the national park issue (Fig. 2).

Type A households were very vulnerable landless or nearly landless households that were highly dependent on nontimber forest products (NTFP) for both cash income and family consumption. Without access to NTFP, they would have to leave the village and work as urban wage earners. Therefore, they were potentially the most affected by the national park issue. Because they did not belong to the influential clans of the community and did not participate greatly in local politics, they were also the most poorly informed villagers about the national park issue, with the least ability to influence the ongoing negotiations.

Type B farming households earned their main income from agriculture and were mainly concerned about the risk of losing land, but this risk was actually not very high. Nontimber forest products were also a concern as a complementary source of cash to compensate for fluctuating farming incomes. They were potentially less affected by the national park issue than type A households. Moreover, being less marginalized than type A farmers, their ability to influence the negotiations was relatively higher. 
Type $\mathrm{C}$ farming households belonged to the local elite. They had enough capital to invest in rather profitable off-farm activities, allowing them consequently to invest in large plantations of litchi or coffee trees. Therefore, they did not feel threatened by the national park issue. Thanks to their social status and their higher level of education, they could be more active in local politics and had a greater ability to influence the issue at stake than the other two types of farmers. Most village leaders belonged to this latter type. However, a distinction should be made between village leaders and other type $\mathrm{C}$ farmers with no formal political responsibilities. We designate these latter as apolitical, although their wealth and status meant that they potentially had significant informal political influence. Within the village, because of their political status, village leaders had the highest influence over the issue at stake.

As for the chief of the national park, he was obviously the most influential, as the law allowed him to take decisions unilaterally, but he was also potentially affected by the issue at stake, with a real risk of losing his job. His objective was to do his duty and enforce the law, but he was afraid of possible violent reactions from the villagers. It had happened previously that villagers started forest fires or shot forest rangers.

Royal Forestry Department officers were in a go-between position. As a state agency, they had to collaborate with the chief of the national park but, unlike him, they tolerated the presence of villagers in the forest areas under their management. They had established rather good relationships with villagers in the past, agreeing on comanagement rules, and they did not want to see the new national park spoiling the results of these past efforts. They were the main supporters of the ComMod process.

From this initial stakeholder analysis, we identified two main kinds of obstacles to the emergence of an equitable concerted process: horizontal obstacles (involving interactions among villagers) and vertical obstacles (involving interactions between villagers and higher level administrations).

The first vertical obstacle was that villagers and village leaders were not aware of the proactive role they could or should have played in the negotiation with the national park. After several decades of highly centralized management of natural resources, in which they had to undergo various top-down forest policies reducing their access to the forest, disobedience or the threat of violence towards authorities were their major means of expression. Therefore, many villagers felt that it was pointless to discuss issues with the board of the national park who would not listen to them in any case. On the national park's side, despite the recent decentralization policies and the adoption of a discourse promoting participatory approaches, the chief of the national park remained very top-down minded. Like many administrators in Thailand, he had strong prejudices against ethnic minorities, seeing them as forest destroyers "who always want more and with whom it is impossible to discuss, because they don't understand anything."

At the horizontal level, we saw that community members had unequal access to information and unequal opportunities to participate in decision making at the village level. There was a danger that the interests of type A farmers would not be taken into account, and in particular that the NTFP issue would be overlooked in the negotiations with the national park, because the village leaders, who did not need to collect NTFP, did not feel concerned about this issue. Although our survey showed that more than one-third of the communities were highly dependent on NTFP, a village leader told us when we first met him: "Nobody collects forest products anymore nowadays. People prefer to buy food in town." This is what Ribot (2001) calls a lack of downwards accountability of leaders.

\section{The nonneutral methodological choices and their effects}

When implementing the ComMod process, we intentionally made several methodological choices to try to overcome these obstacles. In this section, we describe some of these choices and their effects.

\section{Starting with empowerment}

Edmunds and Wollenberg (2001) argue that not all stakeholders should systematically participate in all stages of a multistakeholder process. If not yet empowered prior to such an exercise, the less powerful might not be able to properly defend their interests. We chose to start the process with a series of separate workshops with villagers only. We assumed that if villagers had met national park officers without preliminary debates among them, there were two risks: villagers might have appeared divided and therefore in a weak position in front of the national park's officers, and the interests of the less influential villagers would have been overlooked. In these first workshops, villagers participated in a roleplaying game, playing their own role in two scenarios, with and without national park officers. Individual interviews revealed that these workshops increased the villagers' awareness of the necessity to reflect collectively at village level on the national park issue. They created or enhanced a feeling of collective mobilization to prepare the negotiations with the board of the national park.

\section{Also focusing on the powerful stakeholders}

Dealing with power asymmetries requires a focus also on the powerful stakeholders, in particular those with a strong "best alternative to a negotiated agreement," or BATNA (Fisher and Ury 1981). The chief of the national park had a strong BATNA: if there was no negotiated agreement with the villagers, he would simply apply the law. On the other hand, the poorest villagers had a very low BATNA. It was very important for them that the national park would agree to engage in dialog. Therefore, we put a lot of effort into trying to convince the 
chief of the national park that it was in his interest to dialog with the villagers.

\section{Strategically selecting the participants}

We selected participants carefully to ensure a representation of the diversity of interests in the community. We assumed that, without such a selection, there was a risk that the people who usually do not participate in local politics would not join the workshop. This assumption proved to be right, because when we were discussing the list of participants with village leaders, they systematically considered it pointless to invite poor farmers with low levels of education. Here, the leaders tried to use their power to include or exclude some specific stakeholders; this is a rather common phenomenon.

\section{Using tools highlighting diversity of interests}

Wollenberg et al. (2001) emphasize that participatory approaches often fail to tackle power inequities because their designers aim to reach a consensus too fast. This consensus then often reflects the opinion of the most influential participants. These authors suggest highlighting the diversity of interests instead, to facilitate the emergence of more creative and integrative alternatives. In the described experiment, the role-playing games were intentionally designed to highlight the fact that type A, B, and C farmers had different interests in the national park issue. In particular, playing the game raised the NTFP issue, which might otherwise have been overlooked. We also used a "card-ranking technique." All the problems relating to the establishment of the national park raised by the participants (i.e., risk of losing agricultural land, right to collect NTFP, right to collect wood, etc.) were visualized on small cards, and the participants were invited to rank them. The individual interviews conducted after the workshop revealed that one of the key effects of these workshops was an increased awareness of the points of view of other villagers and the situations affecting them- leading to an enhanced mutual understanding among villagers. In particular, this process increased the village leaders' awareness of the situation for type A farmers. They realized that it was vital for them to obtain the right to collect NTFP in the national park area. To a certain extent, the process increased their downwards accountability toward villagers. The observed change in attitude also relates to the fact that they realized that the NTFP issue was an opportunity to show to the national park officers that villagers had community rules that avoided overexploitation of forest resources. This had the potential to create more trust vis-à-vis the national park, and would increase their chance of being heard on other aspects of the conflict.

Alternating individual interviews and subgroup discussions
with plenary debates
We assumed that, in plenary debates, the less influential
stakeholders would often not dare express their opinion in the
presence of more dominant ones. This assumption also proved correct on several occasions. For example, during the first workshop, two poor women had explained during subgroup discussions that NTFP for food purposes were more important than those for commercial purposes. Immediately after, during the plenary session, they said the opposite. They explained to us during the individual interviews that the village leader had asked them to do so. This village leader had used his relation of patronage with those poor women to influence them. This anecdote illustrates the need to be cautious about any "consensus" or "collective" agreements obtained in a plenary session.

\section{Using tools favoring integrative negotiation processes}

Scholars in the field of negotiation distinguish between distributive and integrative negotiation processes. In a distributive process, the stakeholders just fight to "share the cake" in a zero-sum process. In contrast, in an integrative process, the stakeholders try to reframe the problem at stake to "enlarge the cake" and identify "win-win" solutions (Follett 1940). Integrative processes are more favorable to disadvantaged stakeholders because, otherwise, powerful stakeholders have no interest in questioning the status quo; but integrative processes require a collective learning process in which both sides look beyond their initial positioning to examine the underlying interests determining them. At some stage in the final workshop, the negotiations between villagers and national park officers had reached a standstill because of a frontal confrontation over the issue of the boundary of the park. They just fought to "share the cake" in a distributive negotiation mode. The following day, we suggested that the participants imagine for a while that they had a common space to manage collectively, with no boundary. Agent-based simulations were proposed to the participants to facilitate a collective brainstorming on the forest management rules in this hypothetic common space (Barnaud et al. 2012). The agent-based model represented 15 farming households belonging to different socioeconomic groups who made decisions regarding labor allocation, crop selection, and gathering NTFP. Three scenarios were simulated to test different collective rules regarding the gathering of NTFP and forest encroachment. When presenting the results of simulations, we did not focus on the spatial dynamics so as to avoid the boundary issue dominating the debate. Instead, we focused on the effects of the three scenarios on the different stakeholders through a series of social, economic, and ecological indicators. This allowed the participants to reframe the problem at stake, to move from a debate on the boundary to a debate on the rules for accessing resources, to adopt a more integrative negotiation mode, and to acknowledge that they had mutual interests. At the end of the workshop, they had written and signed a kind of "memorandum of understanding" stipulating that both parties had common interests (to avoid overexploitation of forest resources, to limit forest encroachment, and to control forest fires) and should 
reflect on them and discuss them collectively in the future. Although this paper had a symbolic value only, it was considered as a key achievement by the participants.

This anecdote illustrates the importance of using tools that favor integrative negotiation processes. We argue in Barnaud et al. (2012) that the use of spatially explicit models and representations might in some contexts lead to thinking in terms of boundaries and segregated space and, therefore, prevent thinking in terms of multifunctional space and finding innovative and integrative solutions. Therefore, we suggest using multiple types of supports and representations.

\section{DISCUSSION}

We have shown that local power asymmetries among stakeholders express themselves in a participatory process and can be obstacles to the emergence of an equitable concerted process. We have also shown that the designer of a participatory process can contribute, through his methodological choices, to increasing or to overcoming some of these obstacles, at least to a certain extent. The nonneutrality of these methodological choices implies a continuous and critical reflection on the legitimacy of participatory methods and of their designers. The critical companion posture suggests that, to question and reinforce his legitimacy, the designer should make explicit his underlying assumptions and objectives, so that local stakeholders can question them and reject or accept them as legitimate. Legitimacy is here seen as a constantly evolving product of a coconstruction process between the designers and the participants.

However, this critical companion posture has limitations and raises a number of questions.

(1) Can we really make all our assumptions explicit? The first limitation of this posture is that it is illusory to believe that one can make all one's assumptions explicit. In this case, we emphasized our assumptions regarding power asymmetries, but this is a subjective choice, itself based on assumptions that have not been made explicit. Truly making all one's assumptions explicit would imply questioning also one's cultural norms and values. However, if it is not possible to be explicit about everything, it is possible to make an effort at reflexivity. In this process, we used a logbook in which we wrote down, at each step, the assumptions backing our choices.

(2) Can participants really question these assumptions? First, such assumptions can be rather abstract notions that are not easily understandable by local stakeholders. Second, they might not dare to question and reject these assumptions openly (politeness, researchers' status, etc.). To overcome this limitation, it is very important to monitor the reactions of the participants and to detect in their behaviors all signs of disagreements with the process.
(3) Should we really make all our assumptions explicit? One can also wonder to what extent it is always pertinent to make all assumptions explicit to all stakeholders. For example, when we explained the principles of the process to the chief of the national park, we did not emphasize villagers' empowerment. We rather insisted on the fact that it would be in his interest to scale down the conflict with the villagers. In other cases, some marginalized stakeholders can feel threatened when they have to discuss power issues openly. Flood and Romm (1995) suggest that, in such circumstances, the designer cannot say everything openly and should opt for an oblique use of critical systems thinking. For example, in our case, we never used the word "power" with villagers. We could say this is simply a matter of diplomacy, but we see that there is a thin line between "being transparent with diplomacy," "strategically hiding some piece of information," and "lying to some participants for some strategic reasons," which does not fit with the deontological requirements of the critical companion posture. This means that, in this posture, the designers should be convinced that it is in the participants' interest to join the process. However, this also raises the question of stakeholders who feel that it is not in their interest to participate and who reject any form of dialog.

(4) How should one deal with stakeholders who reject any form of dialog? In this case study, a few families refused to join the process because they had opted for an intimidation strategy towards the national park (threat of violence and forest fires). The rest of their community did not approve of this strategy because it reinforced the hostility of the national park towards them and reduced their possibility of negotiation. These few families never agreed to meet us or to come to the workshops. Some critical authors suggest that, in such situations, there is a need to adopt a very strategic posture and to set up mechanisms to exert pressure on reluctant stakeholders (Leeuwis 2004). Such an option goes against the key deontological principle of the companion posture, which says that the participants in a participatory process should be aware of the objectives of the process and accept them as legitimate. We recognize here that the critical companion posture cannot deal with situations where stakeholders reject any form of dialog. The objective of the critical companion posture is to propose a given form of communication and an arena for discussion based on the principles of equity and voluntarism, even if this arena does not lead to any concrete decision or action. Further, as the process has been implemented despite these few families who did not agree with it, the question is raised as to who the stakeholders are that validate and legitimate the process, and how they are selected, according to whose criteria.

\section{CONCLUSION}

The formulation and implementation of sustainable development requires participatory approaches to enable 
stakeholders to openly, self-critically, and creatively reflect on their desirable, feasible futures. This ideal is also called "reflexive governance." The practice of reflexive governance is not without difficulty, as actors have to deal with political agendas and power games of incumbent stakeholders (Hendriks and Grin 2007). We provide some ideas about how to face this challenge and creatively develop conditions for empowerment and integrative communication. In summary, dealing with power games in a participatory process is like finding balance in a situation of permanent unstable equilibrium, driven by two antagonist forces: on the one hand, the will to let the stakeholders lead the process, taking the risk that the most influential stakeholders will dominate it, and on the other hand, the will to intervene in the discussion arena to empower the less influential stakeholders, taking the risk of weakening the legitimacy of the process. Walking such a fine line, the designer of a participatory process should at each step question and re-invent the conditions of his equilibrium. What specific choices to make at a specific point of time and place depend on the position of the researcher or facilitator in the contextual situation. Cornwall (2004) introduced the concept of cultural-political space to underscore the situated nature of participation. This cultural-political space is a bounded yet permeable arena, populated by particular actors for specific reasons, with associated empowering or disciplining intentions. More research on the diversity of spaces, illuminating the dynamics of power, facilitation, voice, and agency is needed to allow us to get a more intricate insight into how to build genuine sustainable development.

Responses to this article can be read online at: http://www.ecologyandsociety.org/issues/responses. php/5459

\section{Acknowledgments:}

We greatly acknowledge the farmers and administrators that participated to this research for their knowledge and time; Christophe Le Page, Pongchai Dumrongrojwatthana, Guy Trébuil and and François Bousquet for their contribution to the research process; and two anonymous reviewers for their insights and comments on the initial version of the manuscript. We thank the CGIAR Challenge Program on Water and Food and the ASIA-ITC initiative of the European Union for their financial support.

\section{LITERATURE CITED}

Agrawal, A., and K. Gupta. 2005. Decentralization and participation: the governance of common pool resources in Nepal's Terai. World Development 33(7):1101-1114.
Arghiros, D. 2001. Democracy, development and decentralization in provincial Thailand. Curzon Press, Richmond, Surrey, UK.

Barnaud, C., P. D'Aquino, W. Daré, C. Fourage, R. Mathevet, and G. Trébuil. 2011. Power asymmetries in companion modelling processes. Pages 117-140 in M. Etienne, editor. Companion modelling. A participatory approach to support sustainable development. Quæ, Versailles, France.

Barnaud, C., C. Le Page, P. Dumrongrojwatthana, and G. Trébuil. 2012. Spatial representations are not neutral: lessons from a participatory agent-based modelling process in a landuse conflict. Environmental Modelling and Software http://dx. doi.org/10.1016/j.envsoft.2011.11.016

Barnaud, C., G. Trébuil, P. Dumrongrojwatthana, and J. Marie. 2008. Area study prior to companion modelling to integrate multiple interests in upper watershed management of northern Thailand. Southeast Asian Studies 45(4):559-585.

Barnaud, C., A. Van Paassen, G. Trebuil, T. Promburom, and F. Bousquet. 2010. Dealing with power games in a companion modelling process: lessons from community water management in Thailand highlands. The Journal of Agricultural and Extension Education 16(1):55-74. http://dx. doi.org/10.1080/13892240903533152

Barreteau, O., F. Bousquet, and J. Attonaty. 2001. Roleplaying games for opening the black box of multi-agent systems: method and lessons of its application to Senegal River valley irrigated systems. Journal of Artificial Societies and Social Simulation 4(2): 5. [online] URL: http://jasss.soc. surrey.ac.uk/4/2/5.html

Barreteau, O., M. Antona, P. d'Aquino, S. Aubert, S. Boissau, F. Bousquet, W. Dare, M. Etienne, C. Le Page, R. Mathevet, G. Trébuil, and J. Weber. 2003. Our companion modelling approach. Journal of Artificial Societies and Social Simulation 6(2):1. [online] URL: http://jasss.soc.surrey.ac.uk/6/2/1.html

Barreteau, O., P. Bots, and K. Daniell. 2010. A framework for clarifying "participation" in participatory research to prevent its rejection for the wrong reasons. Ecology and Society 15 (2):1. [online] URL: http://www.ecologyandsociety.org/ vol15/iss $2 /$ art1/

Becu, N., A. Neef, P. Schreinemachers, and C. Sangkapitux. 2008. Participatory modeling to support collective decisionmaking: potential and limits of stakeholder involvement. Journal of Land Use Policy 25(4):498-509.

Berkes, F., J. Colding, and C. Folke. 2003. Navigating socialecological systems: building resilience for complexity and change. Cambridge University Press, Cambridge, UK. http:// dx.doi.org/10.1017/CBO9780511541957 
Blaikie, P. 2000. Development, post-, anti- and populist: a critical review. Environment and Planning 32:1033-1050. http://dx.doi.org/10.1068/a3251

Bousquet, F. and C. Le Page. 2004. Multi-agent simulations and ecosystem management: a review. Ecological Modelling 176:313-332. http://dx.doi.org/10.1016/j.ecolmodel.2004.01.011

Bousquet, F., O. Barreteau, C. Le Page, C. Mullon, and J. Weber. 1999. An environmental modelling approach. The use of multi-agents simulations. Pages 113-122 in F. Blasco, and A. Weill, editors. Advances in Environmental and Ecological Modelling. Elsevier, Paris, France.

Boulding, K. E. 1989. Three faces of power. Sage, Newbury Park, California, USA.

Chambers, R., A. Pacey, and L.A. Thrupp. 1989. Farmerfirst: farmer innovation and agricultural research. Intermediate Technology, London, UK.

Checkland, P. 1981. Systems thinking, systems practice. Wiley, Chichester, UK.

Cooke, B., and U. Kothari, editors. 2001. Participation: the new tyranny? Zed Books, London, UK, New York, USA.

Cornwall, A. 2004. Spaces for transformation? Reflections on issues of power and difference in participation in development. Pages 75-91 in S. Hickey, and G. Mohan, editors Participation: from tyranny to transformation? Exploring approaches to participation in development. Zed: London, UK, and New York, New York, USA.

Cornwall, A., and J. Gaventa. 2001. Bridging the gap: citizenship, participation and accountability. PLA Notes 40:32-36.

D'Aquino, P. 2007. Empowerment and participation: how could the wide range of social effects of participatory approaches be better elicited and compared? The ICFAI Journal of Knowledge Management 5(6):76-87.

Daré, W., and O. Barreteau. 2003. A role-playing game in irrigated system negotiation: between play and reality. Journal of Artificial Societies and Social Simulation 6(3):6. [online] URL: http://jasss.soc.surrey.ac.uk/6/3/6.html

Duke, R.D. 1974. Gaming: the future's language. Sage, Halsted Press, New York, New York, USA.

Edmunds, D., and E. Wollenberg. 2001. A strategic approach to multistakeholder negotiations. Development and Change 32(2):231-253. http://dx.doi.org/10.1111/1467-7660.00204

Eversol, R. 2003. Managing the pitfalls of participatory development: some insight from Australia. World Development 31(5):781-795. http://dx.doi.org/10.1016/S0305-750X (03)00018-4
Escobar, A. 1988. Power and visibility: development and the invention and management of the third world. Cultural Anthropology 3(4) 428-443. http://dx.doi.org/10.1525/ can.1988.3.4.02a00060

Faysse, N. 2006. Troubles on the way: an analysis of the challenges faced by multi-stakeholder platforms. Natural Resources Forum 30:219-229. http://dx.doi.org/10.1111/ j.1477-8947.2006.00112.x

Ferber, J. 1999. Multi-agent systems: an introduction to distributed artificial intelligence. Addison-Wesley Longman, Boston, Massachusetts, USA.

Fisher, R. and B. Ury. 1981. Getting to yes: negotiating agreement without giving in. Houghton Mifflin, Boston, Massachusetts, USA.

Flood, R. L., and M. C. Jackson. 1991. Total systems intervention: a practical face to critical system thinking. Systems Practice 4(3):197-213. http://dx.doi.org/10.1007/ BF01059565

Flood, R.L. and N.R.A. Romm. 1995. Enhancing the process of methodology choice in Total Systems Intervention (TSI) and improving chances of tackling coercion. Systems Practice 8(4):377-408. http://dx.doi.org/10.1007/BF02253393

Follett, M. P. 1940. Constructive conflict. Pages 30-49 in H. C. Metcalf and L. Urwick, editors. Dynamic administration: the collected papers of Mary Parker Follett. Harper, New York, New York, USA.

Giddens, A. 1984. The constitution of society: outline of the theory of structuration. University of California Press, Berkeley and Los Angeles, California, USA.

Guijt, I., and M. Shah, editors. 1998. The myth of community: gender issues in participatory development. Intermediate Technology, London, UK.

Grimble, R., and K. Wellard. 1997. Stakeholder methodologies in natural resource management: a review of principles, contexts, experiences and opportunities. Agricultural Systems 55(2):173-193. http://dx.doi.org/10.1016/ S0308-521X(97)00006-1

Gunderson, L., and C. S. Holling. 2002. Panarchy: understanding transformations in human and natural systems. Island, Washington, D.C., USA.

Habermas, J. 1985. The theory of communicative action.. Beacon, Boston, Massachusetts, USA.

Hendriks, C.M., and J. Grin. 2007. Contextualising reflexive governance: the politics of Dutch transitions to sustainability. Journal of Environmental Policy and Planning 9 (3/4):333350. 
Hickey, S., and G. Mohan. 2005. Relocating participation within a radical politics of development. Development and Change 36(2):237-262. http://dx.doi.org/10.1111/

j.0012-155X.2005.00410.x

Hirsch, P. E. 1997. Seeing forest for trees: environment and environmentalism in Thailand. Silkworm Books, Chiang Mai, Thailand.

Innes, J. E. 2004. Consensus building: clarifications for the critics. Planning theory 3(1):5-20. http://dx.doi. org/10.1177/1473095204042315

Jackson, M. C. 2000. Systems approaches to management. Kluwer, New York, New York, USA.

Johnson, N., N. Lilja, J. A. Ashby, and J. A. Garcia. 2004. The practice of participatory research and gender analysis in natural resource management. Natural Resources Forum 28 (3):189-200. http://dx.doi.org/10.1111/j.1477-8947.2004.00088. $\underline{\mathrm{X}}$

Kuper, M., M. Dionnet, A. Hammani, Y. Bekkar, P. Garin, and B. Bluemling. 2009. Supporting the shift from state water to community water: lessons from a social learning approach to designing joint irrigation projects in Morocco. Ecology and Society 14(1): 19. [online] URL: http://www.ecologyandsociety. org/vol14/iss $1 /$ art19/

Leeuwis, C. 2000. Reconceptualizing participation for sustainable rural development: towards a negotiation approach. Development and Change 31:931-959. http://dx. doi.org/10.1111/1467-7660.00184

Leeuwis, C. 2004. Communication for rural innovation. Rethinking agricultural extension. Blackwell, Oxford, UK. http://dx.doi.org/10.1002/9780470995235

Lynam, T., F. Bousquet, C. Le Page, P. d'Aquino, O. Barreteau, F. Chinembiri, and B. Mombeshora. 2002. Adapting science to adaptive managers: spidergrams, belief models, and multi-agent systems modeling. Conservation Ecology 5(2):24. [online] URL: http://www.consecol.org/ vol5/iss $2 / \operatorname{art} 24 /$

Mazoyer, M. and L. Roudart. 1997. Histoire des agricultures du monde: du néolithique à la crise contemporaine. Éditions du Seuil, Paris, France.

McKinnon, J. and B. Vienne. 1989. Hill tribes today. White Lotus, Bangkok, Thailand.

Mitlin, D., S. Hickey, A. Bebbington. 2007. Reclaiming development? NGOs and the challenge of alternatives. World Development 35(10):1699-1720. http://dx.doi.org/10.1016/j. worlddev.2006.11.005

Moity-Maïzi, P. 2000. Méthodes et mécanismes participatifs dans un programme d'écodéveloppement: l'altérité à l'épreuve des faits. Pages 91-118 in P. Lavigne-Delville, N.-E.
Sellamna, and M. Mathieu, editors. Les enquêtes participatives en débat. Ambitions, pratiques et enjeux. Karthala, Paris, France.

Munoz, I., M. Paredes, and R. Thorp. 2007. Group inequalities and the nature and power of collective action: case studies from Peru. World development 35(11):1929-1946.

Nederveen Pieterse, J. 2000. After post-development. Third World Quarterly 21(2)175-1991.

Neef, A., editor. 2005. Participatory approaches for sustainable land use in southeast Asia. White Lotus, Bangkok, Thailand.

Ostrom, E., R. Gardner, and J. Walker. 1994. Rules, games and common-pool resources. University of Michigan Press, Michigan, USA.

Pahl-Wostl, C., M. Craps, A. Dewulf, E. Mostert, D. Tabara, T. Taillieu. 2007. Social learning and water resources management. Ecology and Society 12(2): 5. [online] URL: http://www.ecologyandsociety.org/vol12/iss2/art5/

Pretty, J. N. 1995. Participatory learning for sustainable agriculture. World Development 23(8):1247-1263. http://dx. doi.org/10.1016/0305-750X(95)00046-F

Reed, M. S., A. Graves, N. Dandy, H. Posthumus, K. Hubacek, J. Morris, C. Prell, C. H. Quinn, and L. C. Stringer. 2009. Who's in and why? A typology of stakeholder analysis methods for natural resource management. Journal of Environmental Management 90(5):1933-1949. http://dx.doi. org/10.1016/j.jenvman.2009.01.001

Ribot, J. C. 2001. Integral local development: “accommodating multiple interests" through entrustment and accountable representation. International Journal of Agricultural Resources, Governance and Ecology 1(3/4):327-350. http:// dx.doi.org/10.1504/IJARGE.2001.000018

Sikor, T. and T. Q. Nguyen. 2007. Why may forest devoluton not benefit the rural poor? Forest entitlements in Vietnam's Central Highlands. World Development 35(11):2010-2025.

Ulrich, W. 1995. Critical heuristics of social planning: a new approach to practical philosophy. Wiley, Chichester, UK.

Ulrich, W. 2000. Reflective practice in the civil society: the contribution of critically systemic thinking. Reflective Practice 1(2) 247-268. http://dx.doi.org/10.1080/713693151

Ulrich, W. 2003. Beyond methodology choice: critical systems thinking as critically systemic discourse. Journal of the Operational Research Society 54:325-342. http://dx.doi. org/10.1057/palgrave.jors.2601518

Van Paassen, A., R. Werkman, B. Pedroli, J. van den Berg, E. Steingröver, and C. Leeuwis. 2011. Conclusion: from knowledge for action to knowledge in action. Pages 277-304 
in A. Van Paassen, J. Van den Berg, E. Steingröver, R. Werkman, and B. Pedroli. Knowledge in action. The search for effective collaborative research for sustainable landscape development. Wageningen Publishers, Wageningen, Netherlands. http://dx.doi.org/10.3920/978-90-8686-724-0 12

Von Korff, Y., K. A. Daniell, S. Moellenkamp, P. Bots, and R. M. Bijlsma. 2012. Implementing participatory water management: recent advances in theory, practice, and evaluation. Ecology and Society 17(1): 30. http://dx.doi. org/10.5751/ES-04733-170130

United Nations. 1993. The global partnership for environment and development: a guide to Agenda 21. United Nations, New York, New York, USA.

Walker, B., S. Carpenter, J. Anderies, N. Abel, G. S. Cumming, M. Janssen, L. Lebel, J. Norberg, G. D. Peterson, R. Pritchard. 2002. Resilience management in socialecological systems: a working hypothesis for a participatory approach. Conservation Ecology 6(1):14. [online] URL: http://www.consecol.org/vol6/iss1/art14/

Wollenberg, E., J. Anderson, and D. Edmunds. 2001. Pluralism and the less powerful: accommodating multiple interests in local forest management. International Journal of Agricultural Resources, Governance and Ecology 1(3/4):199222. http://dx.doi.org/10.1504/IJARGE.2001.000012 